\title{
REFLETIR A POLÍTICA DESDE A PERSPECTIVA DO JUDAÍSMO DE LEVINAS
}

\author{
Silvestre Grzibowski e Aline Hernandes Grzibowski \\ Universidade Federal de Santa Maria
}

\begin{abstract}
RESUMO: O objetivo deste estudo é refletir sobre o judaísmo e como esse pensamento pode orientar a organização política da sociedade. Levinas viveu intensamente a religião judaica e foi perseguido filosoficamente e politicamente por ser judeu. Mesmo em tempos sombrios nunca deixou de fazer filosofia e de escrever sobre a religião judaica, fundamentando-a através da ética da responsabilidade. A tese sustentada neste artigo é de que a filosofia e a religião em tempos de crise precisam voltar às fontes como fez Levinas, pois, auxiliam a superar os fanatismos dos fundamentalistas religiosos e políticos e ainda mantém viva a esperança dos seres humanos que passam e sobrevivem às tragédias, como exemplo, os judeus no holocausto. Primeiramente, será apresentado Levinas como um pensador sobre o judaísmo, posteriormente, o extermínio ou o sacrifício, e por fim, a conceituação de Deus, religião e rosto do Outro e como esses apontam um caminho para uma ação política na vida pública.
\end{abstract}

Palavras chave: Emmanuel Levinas, Judaísmo, Religião, Política.

RESUME: Le but de cette étude est de réfléchir au judaïsme et à la manière dont cette réflexion peut guider l'organisation politique de la société. Lévinas a vécu intensément la religion juive et a été persécutée philosophiquement et politiquement pour être juive. Même à l'époque sombre, il n'a jamais cessé de faire de la philosophie et d'écrire sur la religion juive en s'appuyant sur l'éthique de la responsabilité. La thèse de cet article est que la philosophie et la religion en temps de crise doivent revenir aux sources, comme Levinas l'a fait, aidant ainsi à vaincre le fanatisme des fondamentalistes religieux et politiques tout en préservant l'espoir des êtres humains qui passent et survivent. aux tragédies, par exemple, les Juifs dans l'Holocauste. Premièrement, Levinas sera présenté en tant que penseur du judaïsme, puis de l'extermination ou du sacrifice, et enfin, de la conceptualisation de Dieu, de la religion et du visage de l'autre et de la manière dont ceux-ci ouvrent la voie à une action politique dans la vie publique.

Mots-clés: Emmanuel Levinas, Judaïsme, Religion, Politique. 
Para falar sobre o judaísmo em Levinas, é necessário mencionar o holocausto vivido pelos judeus na segunda guerra mundial. Sabe-se que muito se pensou e escreveu sobre esta triste e inesquecível tragédia da história da humanidade, e que atualmente ela permanece sendo refletida. Busca-se assim, neste estudo, evidenciar o judaísmo de Levinas mostrando alguns acontecimentos que marcaram profundamente sua vida filosófica e religiosa. Destacam-se as preocupações que o pensador teve com o mal que estava por vir, a vivência dos horrores nos campos de concentração, a elaboração ou reelaboração do pensamento filosófico após a tragédia que mudou o rumo da humanidade, do pensamento sobre judaísmo e da filosofia pós-holocausto.

O pensamento de Levinas está além do seu e do nosso tempo histórico. Porque, apesar de ter vivido os horrores da segunda guerra mundial, ele não fez um resumo histórico ou sociológico, mas, procurou entender filosoficamente, religiosamente e politicamente a dimensão do episódio e teve a perspicácia de perceber possibilidades de fazer filosofia, política e religião. Ou seja, todo esse acontecimento o impulsionou para produzir uma nova filosofia. Por isso, seu legado filosófico é denso, original e perspicaz. Essas e demais qualidades fizeram com que seu pensamento se consolidasse em todos os continentes nas diversas áreas do saber. É estudado, sobretudo, por sua originalidade, mas também, por possuir um discurso crítico com a tradição e com os sistemas políticos, ainda mais nos dias de hoje em que a humanidade atravessa por um período crítico de profundas crises. Sua filosofia não pode ser reduzida a um discurso conciliador, ao contrário, com seus questionamentos desconcerta e faz com que a sociedade repense suas ações. Embora muito crítico com a tradição filosófica, Levinas pode ser considerado um pensador de esperança.

Nos dias atuais, um observador atento percebe que o mundo cruza por diferentes situações de crises nas diversas áreas do saber. Mais ainda, as relações 
individuais, familiares, sociais, políticas, religiosas e econômicas caminham para um abismo. Esses conflitos atingem profundamente nosso país. Além da crise política, vive-se uma crise ética, moral, religiosa e econômica. Confundem-se ideologias partidárias com as religiosas e vice-versa, assim acirraram-se as guerras entre grupos que disputam espaços para deter o poder a todo custo. Têm-se dificuldades de discernir o certo do errado. A violência espalhou-se em todos os ambientes e penetrou nas instituições públicas como nas escolas, e privadas como nas famílias.

Diante deste cenário, o pensamento de Levinas vem sendo estudado e tem provocado sérios questionamentos que exigem respostas coerentes e convincentes. Por isso, pode-se dizer que esse é um momento oportuno para analisar no que se acredita. Ou melhor, no conteúdo que as religiões ensinam e no que acreditam. Se as religiões pregam a existência de Deus e como os crentes devem segui-lo, deve-se questionar onde, ou em qual teoria esse Deus está fundamentado. Ou mais precisamente, em qual conteúdo as religiões estão alicerçadas? A proposição de Levinas parece ser bem clara ${ }^{1}$. Se a fé religiosa está amparada em Deus, esse é Universal, deve, portanto, estar sendo sustentada pela ética da responsabilidade, pelo respeito mútuo, e na justiça ao próximo, conforme atestam os escritos filosóficos e confessionais do autor. Sendo assim, é possível sustentar que a organização política possa estar fundamentada na religião desde que a ética da responsabilidade e a justiça sejam os pontos norteadores para orientar e distinguir as condutas éticas das não éticas dos cidadãos. A ética amparada na justiça deve ser o princípio básico para governar e administrar a vida pública. Não será esse o ponto que a sociedade ou os gestores das instituições tem se esquecido? É possível conduzir uma sociedade politicamente sem a responsabilidade pelo outro, sobretudo, do outro que está sendo posto a margem? Para Levinas não, porque esta caminhará para um conflito e

\footnotetext{
${ }^{1}$ Existem muitos estudos sobre este tema em Levinas. Cito: VASQUEZ MORO, Ulpiano. El discurso sobre Dios en la obra de Emmanuel Levinas. Madrid: U.P.C.M., 1982. Cf. também GRZIBOWSKI, Silvestre. Dios en la filosofia de Emmanuel Levinas. In: Cecília Cintra Cavaleiro de Macedo. (Org.). La noción de Dios en la filosofia judia. Bogotá: San Pablo, 2017, p. 239-252.
} 
culminará na guerra. Por isso, surge o convite para voltar à Fonte, nesse caso, para o judaísmo e buscar nessa teoria conteúdo para fazer política com justiça.

\section{Emmanuel Levinas: filósofo judeu ou judeu filósofo}

Estamos de acordo com a tese de que não é possível compreender o pensamento filosófico de Levinas sem o judaísmo. Com esta afirmação, esclarecemos o porquê do nosso estudo sobre este tema. Temos consciência que diversos autores têm investigado esta temática, pois Levinas além de ser um pensador-filósofo, foi um judeu pensador, e consequentemente, deixou diversos escritos sobre a religião confessional.

O judaísmo fez parte da vida de Levinas, à educação e as influências da família, da Bíblia, do Talmud, a religião, o monoteísmo a influência de outros pensadores, antes do holocausto e depois. Sendo filho de pais judeus ${ }^{2}$ e desde a sua infância sendo educado na fé confessional, permaneceu nesta, por toda a sua vida. Antes se formou em filosofia e mais tarde no Talmud. Com as noções filosóficas e posteriormente talmúdicas passou a ministrar conferências e ao mesmo tempo publicava algumas obras e textos neste campo e também de filosofia. Conforme apresentam alguns estudiosos de sua vida, Levinas foi um exímio intérprete do Talmud. Pouco se sabe de Levinas por Levinas, temos um pequeno texto que leva o nome de Signature ${ }^{3}$. Acreditamos que estas informações mostram que o judaísmo está fortemente presente em sua vida.

Inicialmente, é importante dizer também que, Levinas jamais reivindicou o título de pensador judeu, pois ele mesmo distinguiu a atividade filosófica do pensamento judeu. E ainda, sobre esta questão ele mesmo respondia que ele era um

\footnotetext{
${ }^{2}$ Cf. MALKA, Salomon. Emmanuel Levinas. La vie et la trace. Paris: Jean-Claude Lattès, 2002. E ainda nesta mesma obra, Malka descreve detalhadamente o ambiente e dos debates em torno do judaísmo da época, cujo ambiente Levinas cresceu e foi educado, por isso Malka afirma que o judaísmo seguiu sendo determinante na vida e nas obras do nosso filósofo.
}

${ }^{3}$ LEVINAS, Emmanuel. Difficile liberté: essais sur le Judaïsme. Paris: Albert Michel, 1976. p. 11. 
judeu que fazia filosofia e não um filósofo judeu ${ }^{4}$. Portanto, o nosso autor refletia sobre judaísmo e filosofia. Porém, os livros confessionais e os livros ditos filosóficos foram publicados em editoras distintas ${ }^{5}$, acreditamos que, judaísmo e filosofia em Levinas se complementam e que o judaísmo o tenha influenciado no pensamento filosófico. Sendo, portanto, impossível separar o judeu do filósofo, muito menos falar de ruptura ou esquecimento das fontes judaicas em sua filosofia ${ }^{6}$.

Não entraremos no mérito de fazer um estudo exegético de quantas vezes Levinas menciona os elementos judaicos em seu pensamento filosófico e vice-versa, até porque não é nosso objetivo. Mas, apenas citaremos que nas suas obras mais importantes como Totalité et Infini e Autrement qu'être ou au-delà de l'essence, a literatura judaica está presente, seja explicitamente ou implicitamente. O mesmo acontece nas suas obras sobre o judaísmo, nas quais o pensador lituano nos convida à uma reflexão filosófica.

Para o filósofo não existe separação entre filosofia e religião. Segundo ele, "existe uma comunicação entre fé e filosofia, e não existe um conflito, mas comunicação entre as tradições" ". Assim, também percebemos que existe uma continuidade entre as duas, e que derivam do judaísmo que não é obrigado a ser uma teologia, um dogma ou um logos que estaria em conflito com a filosofia. Isso porque, quando um pensador menciona uma tradição religiosa nos seus escritos tem-se a tentação de julgá-lo e enquadrá-lo como pensador religioso. Isso em nosso modo de ver é um reducionismo, porque um pensador pode pensar a partir de uma

\footnotetext{
${ }^{4}$ POIRIÉ, François. Emmanuel Levinas, essai et entretiens. Babel: Actes du sud, 1996. p. 13.

${ }^{5}$ Sobre este tema, vejo que é pertinente a teoria de Miguel García. "En mi opinión, dicha diferencia estriba, sobre todo, en que las lecciones transcurren en el horizonte del judaísmo plenamente asumido, mientras que los otros ensayos son, precisamente, aperturas de posibilidades para pensar el judaísmo, según su esencia, en el futuro". GARCÍA-BARÓ, Miguel. La compasión y la catástrofe: ensayos de pensamiento judio. Salamanca: Sígueme, 2007. p. 70.

${ }^{6}$ GONZÁLEZ R. ARNAIZ, Graciano. E. Levinas: humanismo y ética. Madrid: Editorial Cincel, 1988. p. 67.

${ }^{7}$ POIRIÉ, François. Emmanuel Levinas. Qui êtes-vous? Lyon: La Manufacture, 1987. p. 134.
} 
determinada religião e fazer proposições filosóficas sem ser teologia. Afinal, a teologia como ciência tem seus métodos específicos que precisam ser respeitados.

Judaísmo é até certo ponto um caminho de vida em aliança com Deus e semelhante aliança inclui conhecimento, reflexão e questionamento, que a mentalidade tradicional associou com filosofia. Neste sentido, a Bíblia é essencial para o pensamento filosófico como afirma Poirié que é um dos estudiosos de Levinas $^{8}$.

A principal característica do pensamento de Levinas, talvez, seja ter tirado a dialética da tradição, e em certo sentido preservando e renovando seriamente uma relação para o mais importante evento histórico e intelectual do século vinte. Por isso, dirá Richard Cohen que este pensamento

Respondeu profundamente a semelhantes contemporâneos eventos como a primeira guerra mundial, a revolução Russa, a segunda guerra mundial, o holocausto, bomba nuclear, o Estado de Israel, a exploração espacial, e como sua filosofia respondeu criticamente as diversas formulações e ideologias que, sobrepuseram estes movimentos e que serviram e continuam servindo (explicitamente ou implicitamente) como o intelectual ambiente do nosso tempo 9 .

A especial virtude da filosofia de Levinas é que responde e oferece uma alternativa positiva em que o nível do pensamento está na altura ou em um nível mais alto, e que não foi contaminado pelas diversas correntes filosóficas que surgiram neste período ${ }^{10}$. Talvez, uma das probabilidades ou uma das hipóteses que fez Levinas manter sua originalidade seja o pensamento judaico, que esteve fielmente presente em sua biografia.

\footnotetext{
${ }^{8}$ Digo "um dos estudiosos" porque poderia mencionar inúmeros pesquisadores sobre este tema.

${ }^{9}$ COHEN, Richard A. Emmanuel Levinas: Philosopher and Jew. Revista Portuguesa de filosofia. Braga: Universidade de Braga, v. 62, n. 2/4, 2006. p. 484.

10 Richard Cohen (2006) destaca as seguintes correntes: vitalismo, socialismo, liberalismo, democracia, fascismo, fenomenologia, existencialismo, estruturalismo e desconstrução (p. 484).
} 


\section{Repensar o extermínio e o sacrifício}

Os historiadores atestam que o judaísmo europeu do século passado segue paralelamente a perseguição nazi. Levinas diz claramente em sua biografia que toda ela está envolta por esse pressentimento. Este pressentimento é relevante para a sua filosofia. Exatamente porque ele viveu os horrores, sobreviveu à perseguição, e dirá que é necessário voltar às fontes para repensar a filosofia, a religião e o agir político. É evidente que a história em seu todo e, especialmente a história do século XX extraordinariamente viveu momentos complicados, e muito nos tem a ensinar a respeito; sabe-se pelas afirmações de Levinas que o encontro sobrevive ao delírio da Razão hegemônica, exatamente por se dar, precisamente, nos intervalos e intermitências do continuum da violência e da Totalidade. Neste sentido, o encontro entre a filosofia e o judaísmo traz, diria uma 'espiritualidade' própria, uma espiritualidade de concretude máxima, irredutível a conceitos, mas fonte de todo e qualquer conceito que conhece seus próprios limites. Neste âmbito, Levinas expressa a sua preocupação.

Imediatamente depois dos extermínios hitlerianos, que tem podido ter lugar em uma Europa evangelizadora durante quinze séculos, o judaísmo voltou às fontes. O cristianismo o havia habituado a pensar, no Ocidente, que estas fontes estavam secas ou sepultadas embaixo de águas, mas vivas. Encontrar-se sendo judeu depois do massacre nazi significa, pois, voltar a tomar posição com respeito ao cristianismo ${ }^{11}$.

Então, o que significa propriamente o holocausto e quais eram as análises de Levinas sobre hitlerismo?

O hitlerismo é a maior prova - a prova incomparável - que o judaísmo teve que atravessar. A afronta, sob sua forma racista, acrescentou à humilhação um sabor agudo de desespero. A sorte patética de ser judeu torna-se uma fatalidade. Não se pode fugir. $\mathrm{O}$

${ }^{11}$ LEVINAS, 1976, p. 11. 
judeu é inelutavelmente amarrado ao seu judaísmo [...]. Uma juventude que, definitivamente atada aos sofrimentos e às alegrias das nações das quais faz parte [...] diante da realidade do hitlerismo descobre-se toda a gravidade do fato de ser judeu [...]. No símbolo bárbaro e primitivo da raça. Hitler recordou que não se deserta do judaísmo ${ }^{12}$.

Os judeus viveram na carne todos os sofrimentos ao que chamam de Shoah. Primeiramente cabe ressaltar que, os termos por mais densos que possam ser ainda não abarcam a totalidade daquele experimento. Dessa forma, as primeiras dificuldades que encontramos ao delinear essas linhas seria nomear tal acontecimento, talvez essa decorra da incapacidade de atribuir um significado para a "ideologia da limpeza étnica".

Holocausto como tal acontecimento foi inicialmente chamado, o termo deriva da palavra "sacrifício", traduzida no sentido literal, significando "totalmente queimado", se referindo aos sacrifícios de animais que faziam aos deuses, sendo um ato voluntário dedicado ao "Sagrado". Nesse sentido, verifica-se a inadequação do termo, visto que na perseguição nazista aos judeus, não houve nenhum elemento religioso e/ou sagrado, seja por parte das vítimas ou de seus perpetradores.

Outro termo utilizado, a palavra Shoah, também de origem bíblica, significa "extermínio", "catástrofe", hoje também significa a perseguição e assassinato dos judeus na Alemanha de Hitler. Porém, o termo torna-se impreciso, pois as vítimas não foram eliminadas por algum erro ou crime e, mesmo que o tivesse sido, a pena não era executada em nome de um mandado divino. O que aconteceu em Auschwitz, não foi comandado por uma pessoa com poderes sobrenaturais, mas sim, por homens, que inescrupulosamente ordenavam que se infligissem bárbaros sofrimentos aos prisioneiros. Eis as razões para pensarmos sobre as tragédias, elas podem ser evitadas porque são produzidas por homens que pensam e agem com a finalidade de exterminar o outro, sobretudo, o diferente. O extermínio é racional, pensado e produzido pela intelectualidade do ser humano. Por isso, pode ser sim evitado. E

${ }^{12}$ LEVINAS, Emmanuel. L'inspiration religieuse de 1'Alliance. Paix et Droit, n' 8, oct., 1935. p. 4. 
uma das proposições de Levinas é que a religião pensada e vivenciada a partir da ética evitaria tais tragédias.

\section{Judaísmo religião (ética) universal}

Nesta altura da pesquisa perguntamos: como nosso autor compreende o judaísmo? Teria uma definição o judaísmo? Qual a característica principal que tem mantido o judaísmo nestes três mil anos de história sem perder a sua essência? Como entender o judaísmo no nível de linguagem? O judaísmo se expressa somente para um grupo(s) de pessoa(s) ou utiliza uma linguagem universal, no sentido de que fala para toda a humanidade independentemente de ser judeu ou não?

Em primeiro lugar, Levinas dirá que a palavra 'judaísmo', em nosso período inclui diversos conceitos. Mas, designa, antes de tudo, uma religião, que está fundamentada na Bíblia no Talmud e na literatura rabínica.

Ser judeu e ser humano não são posturas distintas. Ou seja, falar a linguagem judaica significa falar para toda a humanidade porque os projetos são compatíveis. Isto porque, a humanidade não necessita de coisas vazias e abstratas. Nesse sentido, ele escreveu que o judaísmo é universal. E a ética em relação à religião, permite compreender o universalismo judeu. "Uma verdade é universal quando vale para todo ser que pensa. Uma religião é universal quando está aberta a todos. Neste sentido, o judaísmo ao vincular o divino à moral, tem pretendido sempre ser universal". Portanto, continua ele, o fato de ser israelita não é um privilégio; "a eleição não é feita de privilégios, mas sim de responsabilidades" ${ }^{13}$. Esse é um dos pontos mais marcantes na filosofia de Levinas, pois, planta a eleição como responsabilidade. Muitos pensadores que criticaram fortemente o judaísmo, de maneira especial o de Levinas, não entenderam esse modo de pensar.

${ }^{13}$ LEVINAS, 1976, p. 38-39. 
As principais características desta religião não sofreram grandes mudanças nestes três mil anos de história. Isso quer dizer que, o judaísmo sempre teve uma característica própria, que o identifica.

Judaísmo significa assim uma cultura: resultado ou fundamento da religião, mas possuidora de um dinamismo próprio. Ao largo do mundo -e no mesmo Estado de Israel- há judeus que se proclamam sem fé e não tem práticas religiosas. Para milhões de judeus, assimilados a civilização ambiente que os rodeia, o judaísmo não pode sequer chamar-se cultura: é uma sensibilidade difusa feita de algumas ideias de recordação, de costumes e emoções, de solidariedade com os judeus perseguidos apenas por serem judeus ${ }^{14}$.

Com estas palavras, diríamos que nosso autor, faz algumas aproximações sobre o significado do judaísmo, mostrando-nos alguns aspectos, como a sensibilidade, a cultura e religião, como um todo, percebidas desde fora como aspectos de uma entidade fortemente caracterizada, difícil de classificar. Exatamente por isso, Levinas pergunta: "Nacionalidade ou religião?" Talvez, resulte difícil responder, ou seja, de dar uma definição exata do que seja. Mas, não restam dúvidas de que o judaísmo é fonte das grandes religiões monoteístas do mundo, e que continua vivo, não só pela sua contribuição em conceitos dos livros, mas também pelos homens e mulheres que, pioneiros nas grandes empresas e também vítimas das grandes convulsões da história, se vinculam como um poço da história santa. Os ensinamentos éticos têm inspirado outras grandes religiões, sobretudo, para olharem para os mais fracos da sociedade e solidarizar-se com eles.

\section{O monoteísmo}

É oportuno neste momento destacar que tudo deve ser pensado a partir da Bíblia. E que a voz de Israel não anuncia, provavelmente, outra coisa mais que o

\footnotetext{
${ }^{14}$ LEVINAS, 1976, p. 42.
} 
monoteísmo. Pode-se afirmar que esta é a principal característica do judaísmo, e que o tem mantido vivo nestes anos de história.

Segundo o nosso autor, o judaísmo sempre tem educado as pessoas para o monoteísmo, pois, não se permite outros deuses. Por isso, o judaísmo descarta a concepção de religião (Deus) no sentido de um sobrevivente. "O Deus dos judeus não é um sobrevivente dos deuses místicos. O monoteísmo estabelece uma ruptura com certa concepção do sagrado. Não unifica nem hierarquiza estes deuses minuciosos e numerosos: os nega" ${ }^{15}$. Por isso, na vida religiosa judia, se dá tanta importância ao exercício da inteligência, aplicada em primeiro lugar, ao conteúdo da revelação, a Torah ${ }^{16}$. Os judeus são iniciados na leitura e no estudo da Torah desde crianças e vão se aprimorando com o passar dos anos. São, portanto, profundos conhecedores deste ensinamento (Lei). Os especialistas -rabinos- que são os conhecedores, sempre estão instruindo os demais. Destaca-se a educação, o conhecimento da tradição como um ponto fundamental para manter a memória e a tradição viva. A Lei é revelada, mas precisa ser conhecida racionalmente.

O monoteísmo que tem conduzido a história da humanidade tem a Bíblia como à fonte, o alicerce, ou para usar uma frase metafórica, a espinha dorsal de Israel, do judaísmo. Neste sentido, ele dirá:

A partir das quais a sombra do Divino se projeta mais além de qualquer teologia e de todo dogmatismo, sobre os desertos da Barbárie: seguir o Altíssimo, não ser fiel mais que ao Único; desconfiar do mito pela qual se impõe o fato consumado, as coações do costume e do terreno, assim o Estado maquiavélico e suas razões

\footnotetext{
${ }^{15}$ Ibid., p. 30.

${ }^{16} \mathrm{O}$ judaísmo na sua história sempre deu uma enorme importância a Torah. Neste sentido, Levinas (1976) dedica um texto ao tema, Aimer la Thora plus que Dieu (cf. p. 189-193); esse texto foi inspirado a partir de um escrito anônimo que foi traduzido a este título Yossel, fils de Yosset Rakover de Tarnopol, parle à Dieu pour La Terre retrouvée. "Nous pensons que là se manifeste, au contraire, la physionomie particulière du judaïsme: le rapport entre Dieu et l'homme n'est pas une communion sentimentale dans l'amour d'un Dieu incarné, mais une relation entre esprits, par l'intermédiaire d'un enseignement, par la Thora. C'est précisément une parole, non incarnée de Dieu, qui assure un Dieu vivant parmi nous. La confiance en Dieu qui ne se manifeste par aucune autorité terrestre ne peut reposer que sur l'évidence intérieure et la valeur d'un enseignement". Ibid., p. 192.
} 
de Estado; seguir o Altíssimo, sabendo que não há mais nada excelso que a aproximação do próximo, que a preocupação pela sorte 'da viúva, do órfão, o estrangeiro e o pobre' e que nenhuma aproximação com as mãos vazias é uma aproximação; é sobre a terra, em meio dos homens, onde se desenvolve a aventura do espírito; o trauma que foi a escravidão no país do Egito constitui minha humanidade mesma ${ }^{17}$.

Tendo como plano de fundo este belo texto, se pode afirmar que, justamente aqui se encontra uma fonte essencial que marca e caracteriza como inesgotável para a filosofia que fundamenta a religião e o agir do ser humano. Por isso, não tememos em afirmar que as ações dos seres humanos poderiam ser totalmente diferentes se escutassem e seguissem os clamores dos mais fracos da sociedade. Infelizmente, hoje não se entende verdadeiramente a religião, apenas se sustenta uma soberba política onde se defendem os privilégios dos mais fortes e poderosos da sociedade, deixando assim à margem os fracos. Mais ainda, as religiões e mesmo o nome de deus é utilizado para justificar a barbárie. Levinas conceitua e define ou aproxima a sua filosofia com as seguintes palavras que assim as menciono: Deus-monoteísmo-éticareligião-proximidade-relação-responsabilidade ${ }^{18}$. Este vocabulário compõe a verdadeira filosofia de Levinas. E assim, o leitor toma consciência que o judaísmo está presente na filosofia e que para exercer a atividade política na vida da polis estas orientações são indispensáveis. Esse vocabulário faz parte da sua essência filosófica, sobretudo, para compreender o seu pensamento. Sendo assim, seria uma tarefa quase impossível exercer a atividade filosófica e política sem essas palavras chaves que conduzem o seu ditado. Que não são simples palavras, mas conceitos que regem a sua filosofia. Ao Altíssimo, ao Único ao qual se refere está perto de mim, pois, é o próximo. E quem

\footnotetext{
${ }^{17}$ LEVINAS, 1976, p. 44.

${ }^{18}$ Cursivas são minhas. Sei que não é correto escrever estas palavras e interligá-las com o hífen, mas peço licença do leitor, porque quero transmitir uma ideia de que todas estas palavras estão interligadas. Sobre estes pontos, poderíamos ainda acrescentar a universalidade, no sentido de que a filosofia de Levinas é universal.
} 
é o próximo? Para Levinas é o pobre, o órfão, a viúva e também o estrangeiro, ou seja, os vulneráveis da sociedade.

Por isso, neste momento da investigação, faz-se oportuno dizer como Levinas apresenta Deus. É o Deus do judaísmo, pois, este é Único, porém, que se revela no rosto do Outro. A filosofia de Levinas em nenhum instante teria a preocupação de buscar provar a existência de Deus ou de buscar argumentos filosóficos ou teológicos para provar a sua existência, ou para dizer que ele existe. Parte do princípio de que é o Único e para segui-lo fielmente devemos nos relacionar com os outros. Contudo, essa relação exige justiça social, ou seja, devemos estar atentos ao próximo que nos olha e clama por justiça.

Deste modo, a filosofia de Levinas circula por este eixo fundamental monoteísmo ético-. Como temos visto o monoteísmo judaico, ou bíblico sempre se manteve fiel durante toda a sua história, e parece que a filosofia de Levinas volta a esta fonte para dar sustentáculo ao seu pensamento. Este de fato é um chão firme, a rocha na qual Levinas constrói o edifício filosófico. É a tradição judaica presente na filosofia moderna. Como pensar na ética sem o monoteísmo religioso, de modo especial o judaico?

Para o judaísmo é fundamental a relação com o outro, mas, esta relação deve estar solidificada na ética. E mais; o outro será condição indispensável para chegar até Deus. Até porque, se o homem está sedento de Deus, deverá experimentar a presença de Deus através da relação com outro homem. Neste sentido, para o judaísmo o relacionamento que parte do princípio ético, é o que faz a diferença, é distinto de qualquer outra filosofia. No caso concreto, o judaísmo se diferencia da filosofia de Plotino, e da filosofia ocidental até Hegel. "Estas estruturas marcam, com efeito, o retorno a si do pensamento absoluto, a identidade do idêntico e do não idêntico na consciência de si, reconhecendo-se pensamento, infinito, "sem outro", em Hegel" ${ }^{19}$. Essa filosofia que faz de si mesmo a entrada do reino do absoluto e que

\footnotetext{
${ }^{19}$ LEVINAS, Emmanuel. Entre nós: ensaios sobre a alteridade. Trad. Pergentino Stefano Pivatto (coord.). Petrópolis: Vozes, 2004. p. 164-165.
} 
anuncia que nada existe o que é distinto de si, mas somente o si mesmo. De modo que, a transcendência para o judaísmo, faz o caminho ao revés, ou seja, relacionarse com o outro. Assim, na medida em que nos relacionamos com o outro, nos relacionamos com Deus ${ }^{20}$. Quando Levinas fala da relação, talvez o leitor estranhe a repetição constante deste vocábulo, mas o autor utiliza-o justamente para enfatizar a importância que este tem para a sua filosofia, sem dúvida nenhuma, revela toda sua profundidade. Para Levinas, tudo o que conhecemos sobre Deus e tudo o que podemos entender de sua palavra ou dizer sobre Ele, deve buscar uma expressão ética. Para clarificar esta questão, diria ainda que, quando Moisés está no Monte Sinai e escuta a voz de Deus, não existe outra coisa a não ser as tábuas da Lei. O conhecimento de Deus chega para o povo como um mandamento, como Mitsváh. Portanto, conhecer a Deus é saber o que há para fazer. Neste sentido, viver o judaísmo é estar presente neste mundo. "Que o judaísmo aporta ao mundo, não é a generosidade fácil do coração, nem de visões metafísicas inéditas, mas um mundo de existência guiado pela prática dos mandamentos" ${ }^{21}$.

Graças a experiência de uma existência regida por obrigações, o judaísmo pode fazer uma concepção absoluta da ética. E mais, a abertura ao transcendente a heteronomia - é o coração desta tradição pela experiência vivida e continuação do rito.

Além disso, a relação ética se apresenta absolutamente no outro, mas isto não nega nossa liberdade. Pois a relação ética é anterior a guerra, e o rosto do outro, ou o rosto do próximo não é alérgico. Neste sentido, para Levinas o Deus do céu é acessível sem perder a sua transcendência, não nega a liberdade do crente. Assim, a justiça manifestada no outro, no próximo, nos dá uma proximidade insuperável de Deus. Por isso, o sentido da relação ética está imbuído pela justiça, pois, Deus não pode receber nada de mãos que praticam a violência. Portanto, a relação com o

\footnotetext{
${ }^{20}$ LEVINAS, 1976, p. 33.

${ }^{21}$ LEVINAS, Emmanuel. Descobrindo a existência com Husserl e Heidegger. Trad. Fernanda Oliveira. Lisboa: Instituto Piaget, 1998. p. 176.
} 
divino atravessa a relação com os homens e coincide com a justiça social. Levinas toma como ponto de partida Moisés e os profetas que em nenhum momento se preocuparam com a imortalidade da alma e sim com o pobre, com a viúva, com o órfão e com o estrangeiro. De modo que, a relação com o outro está plenamente carregada de responsabilidade.

\section{Considerações finais}

Revisitar os textos de Levinas sobre o judaísmo é um compromisso teórico para os estudiosos do seu pensamento. Os textos são riquíssimos e de uma sabedoria incalculável. Eles nos fazem pensar no estudo e na pesquisa da filosofia, da religião e da política. Como mencionamos na introdução deste estudo, vivemos hoje um período conturbado da história e o legado teórico de Levinas nos faz pensar no modo como estudamos e seguimos a religião e a política.

O autor sustenta que cada um poderá manter a sua religião desde que essa seja auxiliada pela ética da responsabilidade. Esse artigo mostrou o judaísmo como uma possibilidade, mas isso não significa que exclui as demais religiões, porque para Levinas ser judeu é ser responsável pelo outro. Em nosso modo de ver, Levinas faz as seguintes proposições para os tempos de crise ou de bonança: a humanidade tem a obrigação de consultar as lições dadas pelos antigos, de modo que possam seguir os ensinamentos e que as relações sociais e políticas possam estar sendo consolidadas no respeito mútuo. Ou seja, para certificar-se do caminho ético a humanidade deverá consultar os escritos, ler e refletir sobre as Fontes que são os textos antigos, como, por exemplo, o Talmude; e em segundo lugar não se esquecer da história, sobretudo, dos acontecimentos trágicos que marcaram a humanidade para que não se repitam mais. Infelizmente, assistimos as barbáries que crescem de maneira assombrosa. Os líderes mundiais que hoje pregam a Paz, a Justiça, infelizmente não são escutados. O pensamento de Levinas é um clamor que em meio à escuridão, lança um grito de alerta chamado esperança. Pensamento que não é apenas uma utopia, mas uma 
urgência nos tempos atuais. Valores que precisam ser ensinados e cultivados. A humanidade é a verdadeira responsável pelas atrocidades ocorridas no decorrer da história, no entanto, é em suas mãos que se encontra a chave para a Paz. Apenas devemos começar a fazer a diferença.

\section{REFERÊNCIAS}

COHEN, Richard A. Emmanuel Levinas: Philosopher and Jew. Revista Portuguesa de filosofia. Braga: Universidade de Braga, v. 62, n. 2/4, p. 481-490, 2006.

GONZÁLEZ R. ARNAIZ, Graciano. E. Levinas: humanismo y ética. Madrid: Editorial Cincel, 1988.

GARCÍA-BARÓ, Miguel. Del dolor, la verdad y el bien. Salamanca: Sígueme, 2006.

La compasión y la catástrofe: ensayos de pensamiento judío. Salamanca: Ediciones Sígueme, 2007.

GRZIBOWSKI, Silvestre. Dios en la filosofia de Emmanuel Levinas. In: Cecília Cintra Cavaleiro de Macedo. (Org.). La noción de Dios en la filosofia judía. Bogotá: San Pablo, 2017, p. 239-252.

LEVINAS, Emmanuel. A l'heure des nations. Paris: Minuit, 1988.

. Alterité et transcendance. Montpellier: Fata Morgana, 1995.

. Autrement qu'être ou au-delà de l'essence. Den Haag: M. Nijhooff, 1974.

. A l'heure des nations. Paris: Minuit, 1988.

. De Dieu que vient à l'Idée. Paris: Vrin, 1982.

. Descobrindo a existência com Husserl e Heidegger. Trad. Fernanda Oliveira. Lisboa: Instituto Piaget, 1998.

. Difficile liberté: essais sur le Judaïsme. Paris: Albert Michel, 1976.

Du Sacré au Saint. Cinq Neuvelles Lectures Talmudiques. París: Minuit, 1977. 
. Entre nós: ensaios sobre a alteridade. Trad. Pergentino Stefano Pivatto (coord.). Petrópolis: Vozes, 2004.

. Hors sujet. Montpellier: Fata Morgana, 1987.

L'au-delà du Verset, Lectures et Discours Talmudiques. Paris: Les éditions de Minuit, 1982.

Les imprévus de l'histoire. Préface de Pierre Hayat: "Épreuves de l'histoire exigences d'une pensée ». Montpellier: Fata Morgana, 1994.

. L'inspiration religieuse de l'Alliance. Paix et Droit, n. 8, oct. 1935.

Totalité et Infini. Essai sur l'extériorité. Den Haag: M. Nijhoff, 1961.

MALKA, Salomon. Emmanuel Levinas. La vie et la trace. Paris: Jean-Claude Lattès, 2002.

POIRIÉ, François. Emmanuel Levinas, essai et entretiens. Babel: Actes du sud, 1996. Emmanuel Levinas. Qui êtes-vous?. Lyon: La Manufacture, 1987.

VASQUEZ MORO, Ulpiano. El discurso sobre Dios en la obra de Emmanuel Levinas. Madrid: U.P.C.M., 1982. 